\title{
ANÁLISE AMBIENTAL DO TRECHO URBANO DO RIO BARRA NOVA NO MUNICÍPIO DE CAICÓ/RN
}

\author{
Ana Clara Damasceno Souza de Medeiros ${ }^{(a)}$; Ana Caroline Damasceno Souza ${ }^{(b)}$; Roberta Kelly \\ Cardoso Fernandes ${ }^{\text {(c)}}$; Diógenes Félix da Silva Costa ${ }^{\text {(d) }}$ \\ (a) Grupo de Pesquisa em Geoecologia e Biogeografia de Ambientes Tropicais - TRÓPIKOS /UFRN, \\ clarasouza.lama@gmail.com \\ (b) TRÓPIKOS/UFRN, anacaroline.lama@ gmail.com \\ (c) TRÓPIKOS/UFRN, robertak2013@hotmail.com \\ (d) Líder do TRÓPIKOS/UFRN, diogenes.costa@ pq.cnpq.br
}

\section{EIXO: BACIAS HIDROGRÁFICAS E RECURSOS HÍDRICOS: ANÁLISE, PLANEJAMENTO E GESTÃO}

\begin{abstract}
Resumo
Um recurso natural indispensável para a sobrevivência da vida é a água, sua utilidade é insubstituível para os seres que dela dependem. Desde as primeiras civilizações, as comunidades procuravam se estabelecer próximos a lugares que apresentavam disponibilidade hídrica. Neste estudo buscou-se realizar a análise preliminar dos impactos ambientais no trecho urbano do rio Barra Nova em Caicó/RN, em que foi possível constatar durante seu percurso vários problemas existentes em decorrência da falta de ordenamento territorial, como o lançamento de esgotos domésticos sem tratamento, poluição de lixo e entulho, além da presença de animais soltos. A situação em que se encontra o rio demonstra que devemos tomá-la como uma situação emergencial, necessitando de ações e políticas públicas voltadas para a adequação do planejamento urbano com intervenções imediatas, provocando debates políticos intermunicipais para buscar soluções para que seja possível uma revitalização, pois seguindo seu curso esta água é utilizada para o abastecimento de várias cidades.
\end{abstract}

Palavras chave: Rios Urbanos, Ocupação Desordenada, Degradação.

\section{Introdução}

A água é um recurso natural indispensável para a sobrevivência da vida onde entre suas utilidades se destaca o abastecimento público, a irrigação, a produção de energia elétrica e as atividades de lazer e recreação, bem como a preservação da vida aquática. Entretanto, nos últimos tempos a humanidade vem utilizando esse recurso de forma inadequada, o que vem a ocasionar a escassez, gerando sérios problemas de ordem ambiental, social e econômica (PRADO, 2004). Segundo Rebouças et al. (2006), o termo "água" refere-se, ao elemento natural, desvinculado de qualquer uso ou utilização e o termo "recurso hídrico" é a consideração da água como bem econômico, passível de utilização para tal fim.

Especificamente no interior da Região Nordeste do Brasil, o clima semiárido determina a influência e a forma que o homem modifica a paisagem e utiliza os recursos naturais, como a água, o solo 
e a vegetação (SILVA, 2006). A mata ciliar é desmatada para a construção de residências e currais em áreas de vulnerabilidade, devido ao longo período de secas prolongadas, muitos anos sem o rio completar o seu curso no nível máximo (leito maior), evidenciando a falta de ordenamento territorial (REBOUÇAS et al., 2006). Destaca-se ainda que estes importantes ecossistemas ainda prestam uma série de serviços para o bem estar das comunidades humanas que vivem nas suas margens (OLIVEIRA et al., 2016). Dentro desse contexto de degradação dos corpos hídricos, surge então a necessidade de se fazer uma análise mais detalhada da área de estudo, onde o objetivo de trabalho foi realizar a análise preliminar dos impactos causados pela ação antrópica no trecho urbano do Rio Barra Nova em Caicó/RN.

\section{Procedimentos metodológicos}

O local a ser estudado é um recorte da Microbacia Hidrográfica do Rio Barra Nova (RN/PB) que está inserida na sub-bacia do Rio Seridó e englobada na Bacia Hidrográfica do Piancó-Piranhas-Açu, onde abrange oito municípios localizados em dois estados. Na Paraíba: Junco do Seridó, Santa Luzia, São José do Sabugi e Várzea; no Rio Grande do Norte: Santana do Seridó, Ouro Branco, Jardim do Seridó e Caicó (Figura 01).

Considerado o maior município da microbacia, Caicó-RN possui 67.747 habitantes (IBGE, 2017), situada no interior do estado a $282 \mathrm{~km}$ de Natal, capital do estado. No trecho urbano do rio Barra Nova neste município, verificou-se que 05 bairros e a área central da cidade estão situados nas suas margens (bairros Acampamento, Paraíba, Soledade, João XXIII, Barra Nova e Centro), abrangendo uma área de aproximadamente $2,5 \mathrm{~km}$ de extensão.

As etapas metodológicas tiveram início com uma revisão bibliográfica, em que foram utilizados livros, teses, dissertações, monografias, artigos científicos entre outros materiais que foram de fundamental importância teórica. Foi realizado um levantamento in situ utilizando 01 aparelho GNSS para reconhecimento da área, percorrendo o trajeto do curso do Rio para observar e analisar de forma crítica os problemas existentes, foi feito o sobrevôo com Drone (Ar Parrot 2.0) nos locais de difícil acesso e a aplicação da técnica de lista de checagem (SÁNCHEZ, 2013). Para gerar o produto cartográfico de representação da área, foi utilizado o software ArcGIS 10.3 (Versão Acadêmica) na elaboração do mapa de localização, onde foi utilizado o shapefile do IBGE (2010) e imagens do Google Earth Pro. 

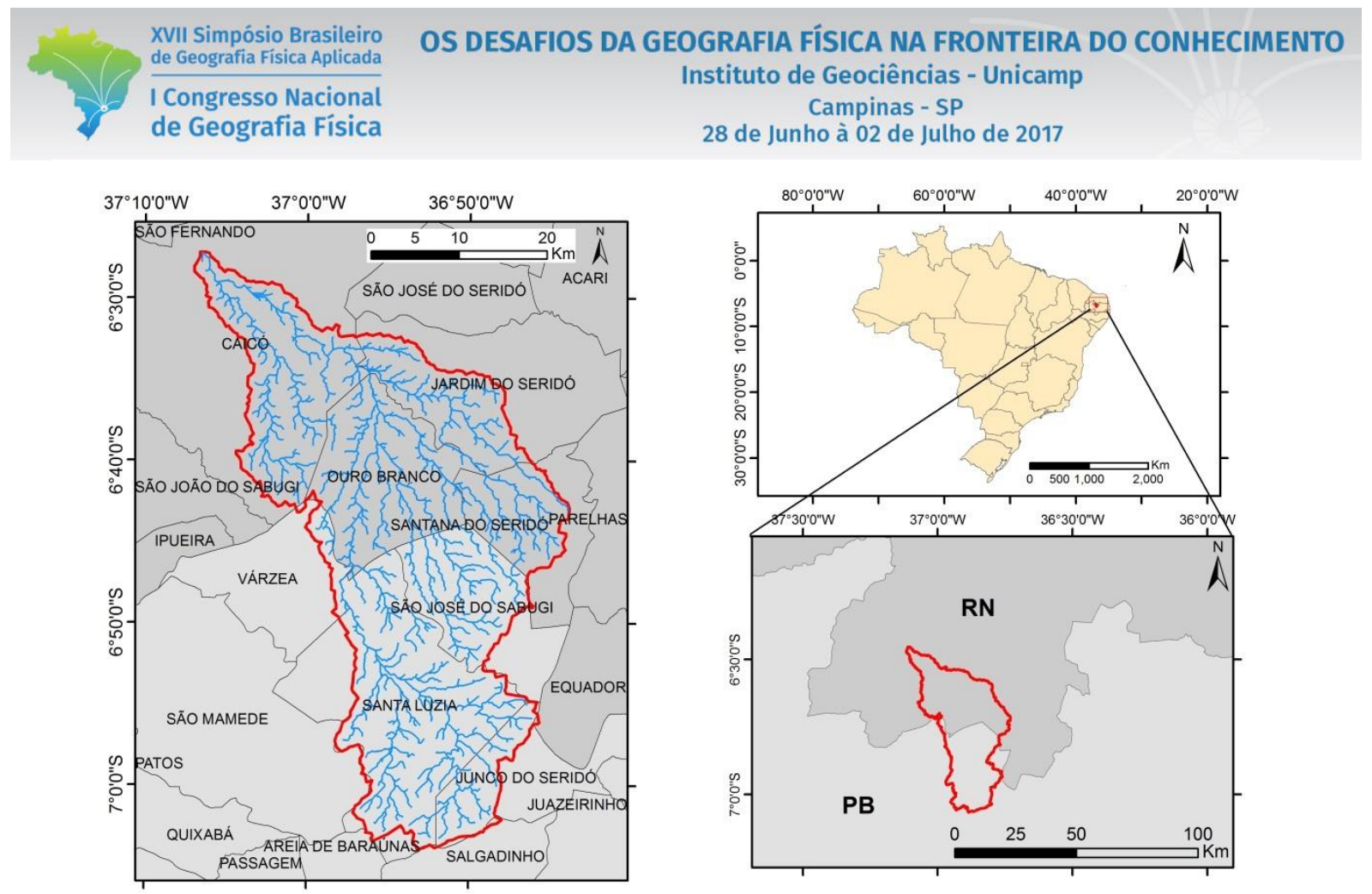

Legenda

- Rede de drenagem $\square$ Estado da PB

Microbacia Barra Nova
Coordenadas Geográficas Datum: WGS 84 - Zona 24S Malha digital: IBGE 2010
Elaboração:

Ana Caroline D. Souza

Ana Clara D. Souza

Figura 1 - Mapa de localização da Microbacia do Rio Barra Nova (RN/PB)

\section{Resultados e discussão}

A atividade pecuária fez parte do desenvolvimento do município de Caicó, porém no final do século XIX e inicio do século XX, o plantio de algodão se popularizou na região, época em que houve a instalação da usina de beneficiamento de algodão próximo ao rio Barra Nova, sendo este o início da ocupação dos bairros Barra Nova e João XXIII, com a doação de terrenos pelas autoridades da época para as famílias que vinha da zona rural (FARIA, 2011; FERNANDES, 2014). Durante o século XX, o trecho urbano do Rio Barra Nova serviu como área de lazer e divertimento, tendo uma grande importância histórica, socioeconômica e cultural.

A urbanização sem planejamento e a ausência de fiscalização e políticas apropriadas, contribuíram para a degradação ambiental, constando a urgência em seu ordenamento, em busca de amenizar os impactos negativos trazidos ao meio ambiente, onde são esgotadas suas potencialidades e qualidade.

Na observação de campo realizada às margens do rio, nota-se que em alguns trechos não há a existência de água, o leito do rio está assoreado, este é um processo natural, mas com a retirada da cobertura vegetal das margens para o cultivo de capim elefante (Pennisetum purpureum Schum/Poaceae) 
em seu leito, acelerou o processo de assoreamento. Além da presença de algumas passarelas de concreto sem abertura de vazão, que ligam um bairro ao outro, que funcionam como barreiras, pois impedem que o curso do rio siga naturalmente.

Ainda é possível constatar vários problemas existentes em decorrência da falta de ordenamento territorial, algumas residências tem sua encanação direcionada para o rio ou para as galerias sendo lançados efluentes líquidos (esgotos) "in natura" no curso do rio. Esta atividade é de alto impacto para o ecossistema, pois altera os níveis dos elementos químicos, desestabilizando toda a biota existente.

Devido a herança da intensa atividade pecuarista existente na área, até os dias atuais, é possível encontrar bovinos e outros animais ao longo de todo o percurso das margens do rio, com isso, há uma grande quantidade excrementos, os quais contribuem com o aumento da concentração de nutrientes orgânicos, acrescido também do descarte de resíduos sólidos (lixo) que se verifica ao longo de todo o curso do rio. Isso ocorre principalmente pela ineficiência da coleta periódica semanal, como também pela ausência do saneamento básico e dos tipos de moradias encontradas na área (SILVA; SANTOS, 2002).

\section{Considerações Finais}

A degradação de ambientes aquáticos é uma problemática preocupante devido ao aumento crescente da expansão urbana desenfreada, como foi o caso dos bairros às margens do rio Barra Nova, em que ocorreu no século XX um êxodo rural devido o desenvolvimento da cotonicultura.

Objetivando realizar uma analise preliminar do trecho urbano do rio Barra Nova no município de Caicó, foi constatado que a presença humana alterou o ambiente, que antes era possível utilizá-lo para recreação e pesca mas hoje não é possível devido a poluição existente. Observou-se que o curso do rio está comprometido, além da presença de bioindicadores de contaminação do ecossistema como as macrófitas emersas.

\section{Bibliografia}

FARIA, C. E. Os eventos geográficos e a expansão urbana de Caicó: Desigualdades e Coexistências na URBE. Dissertação (Mestrado em Geografia) - Instituto Federal do Rio Grande do Norte - 2011. 177 f. IFRN, Natal, 2011. p.83-130.

FERNANDES, R.K.C. Análise da ocupação das margens do Rio Barra Nova no trecho urbano de Caicó - RN. Monografia (Bacharel em Geografia) - Universidade Federal do Rio Grande do Norte. Centro de Ensino Superior do Seridó, Caicó, 2014.

OLIVEIRA, A.M.; COSTA, D.F.S.; ARAÚJO,W.S.; SILVA, E.E.S. Análise dos serviços ecossistêmicos em reservatórios da Região Nordeste Semiárida do Brasil. REGNE, v. 2, n. especial, p.1447-1458, 2016. 
PRADO, R. B. Geotecnologias aplicadas à análise espaço-temporal do uso e cobertura da terra e qualidade da água do reservatório de Barra Bonita, SP, como suporte à gestão de recursos hídricos. 2004. 172 f. Tese (Doutorado) - Centro de Recursos Hídricos e Ecologia Aplicada, Escola de Engenharia de São Carlos, Universidade de São Paulo, São Carlos. 2004.

REBOUÇAS, A. C.; BRAGA, B. B.; TUNDISI, J. G.; Águas Doces no Brasil. 3 ed. São Paulo: Escrituras, 2006.

SÁNCHEZ, L. E. Avaliação de Impacto Ambiental: conceitos e métodos. 2 ed. São Paulo: Oficina de Textos, 2013.

SANTOS, A. R.; CUNHA, D. M.; CRUZ, F. M. O trecho urbano do Rio Doce no bairro São Tarcísio em Governador Valadares/MG: análise descritiva da degradação ambiental. In XVI SIMPÓSIO BRASILEIRO DE GEOGRAFIA FÍSICA APLICADA, 2015, Teresina/PI. Anais... Terezina/PI, 2015.

SILVA, R. M. A. Entre o combate à seca e a convivência com o semi-árido: transições paradigmáticas e sustentabilidade do desenvolvimento. 2006. 298 f.. Tese (Doutorado em Desenvolvimento Sustentável)Universidade de Brasília, Brasília, 2006. 